\title{
Problem-based Multidisciplinary Participation in Aerospace Design
}

\section{Mr. Wiaam Elkhatib, Indiana University-Purdue University Indianapolis}

Wiaam Y. Elkhatib is a biomedical engineering student and aspiring physician-engineer at Purdue University, Indianapolis. Wiaam's research with the Richard G. Lugar Center for Renewable Energy quantitates photovoltaic efficacy in urban environments, while as an intern through the Indiana University School of Medicine, he evaluates the musculoskeletal effects of various chronic kidney disease interventions. An avid campus educator and leader, Wiaam serves as president of both the Students for the Exploration and Development of Space (SEDS) and Biomedical Engineering Society (BMES) chapters. He is also an academic success mentor who facilitates incoming university students in achieving educational fulfillment while encouraging involvement with undergraduate campus research.

Mr. Steven Anthony Zusack, Indiana University-Purdue University Indianapolis

Mechanical Engineering graduate. Current research includes design project of a 1G Spinning Space Station and Lunar Polar Ice Extraction for Moon Fueling Station. Aspirations of pursuing $\mathrm{PhD}$ in the field of Aerospace Engineering with a focus on Spacecraft Design. Currently working at NASA Johnson Space Center performing structural testing for a manned spacecraft.

Prof. Peter J. Schubert, Indiana University-Purdue University Indianapolis

Schubert is a Professor of Electrical and Computer Engineering and serves as the Director of the Richard G. Lugar Center for Renewable Energy (www.lugarenergycenter.org) and the faculty advisor for Students for the Exploration and Development of Space (SEDS) at IUPUI. He holds 40 US Patents, a Professional Engineering License (Illinois), and has published over 95 technical papers and book chapters. Schubert has managed research projects from USDA, NASA, DOE, and DoD.

Mr. Brock Schaffer,

Miss Emiliya V. Akmayeva, Students for the Development and Exploration of Space

Mr. Patrick John Proctor, Indiana University-Purdue University Indianapolis

BS Physics 2015 - Purdue University BS Informatics 2010 - Indiana University

Interest areas: Aerospace engineering, human space flight, space logistics

Guy Nicholas Wiss, SEDS 


\title{
Problem-based Multi-disciplinary Participation in Aerospace Design
}

\begin{abstract}
This work explores the knowledge development of a diverse team of undergraduate students involved in a university organization in pursuit of a RASC-AL engineering challenge by NASA to develop a 1-G deep space station. This habitat would need to be fully self-sufficient within five years of its initial launch and have a 20-30 year operational time span. The breadth of considerations is well-suited for a large team with a broad range of skills. Factors considered include potential fuel sources, location in space, materials, radiation hazards, purpose of construction, physiological and psychological concerns, sustainable agriculture methods, as well as an efficient rotation and docking system. Teams then collectively collaborated to present and successfully justify the most unique, practical, and cost-effective $1 \mathrm{G}$ space station design. Selfrun by a student organization open to all majors, this design activity builds upon a multi-year history of aerospace project work. Student leadership developed a framework within which each participant can find a useful task and feel part of a larger whole. The aim of the study is to assess effective means for attracting and retaining a large, diverse team in ways which are sustainable during leadership turnover, and to reach for ever more-challenging goals. Past successes within the organization helped to attract and retain a range of interested and motivated students. Student educational outcomes were assessed both before and after the design project. Multiple choice and ranking questions with on-line surveys allow for tracking of perceptions and motivation, and identifying factors contributing to sustained involvement. Individual passions were woven into the overall design approach to provide a sense of ownership and a feeling of contribution which are hypothesized to be strongly correlated with overall success of the team. In this work the extent to which each student's degree program is utilized is characterized, as well as their particular area(s) of interest, and compared with measures of output and contribution to the final result.
\end{abstract}

\section{Introduction}

The future of manned space travel will require long durations of living and working in space. To help eliminate the negative effects of the microgravity environment, a spinning structure would simulate a gravitational pull. As a first major step in this direction, a spinning space station would allow a means by which to study the long term effects of this kind of environment while in relatively close proximity to the Earth. It would be the first truly long-duration space habitat ever constructed. Contemplating a 20-30 year timespan, beginning in 2015, an architecture was developed to continuously support between 16-24 people living in a $1 \mathrm{G}$ space station. Independence from Earth resupply will have been achieved after five years of successful operation.

The design project revolves around creating a novel architecture which simulates Earth-like gravity. Necessary design considerations included incorporating the practical constraints of time, money, staff availability, and aiming to engage undergraduate students in active learning. Active learning refers to the level of academic student engagement in and out of classroom within the subjects, as compared to passive lecturing of information. Specific facets of such learning 
incorporated into this project included brainstorming, zealous discussion, teaching others, frequent research and documentation, collaborative teamwork, focused listening, exchange of constructive criticism, notetaking, and software design implementation. This aerospace project strongly contrasts with the standard teaching method of lecturing. Previous engineering education literature and research on active learning have consistently revealed that many individuals learn best and become proficient in skills by practicing them in a real setting and by engaging in group projects ${ }^{13,14,15}$. Design projects also help students to visualize their main result, therefore engaging all their attention on the product. Learning through visualization reduces the burden of math and memorization helping to expedite learning ${ }^{13}$. It is consequently important to give students the opportunity to study outside of the typical classroom setting while tackling real-world problems. It becomes the student's responsibility to conduct research, develop a plan of action, and collaborate within a team. This approach helps discover natural talent, applies and expands on classroom knowledge, and may help launch a career in aerospace or engineering based on that discovery.

\section{Methods}

Students were initially surveyed solely to gauge project interest based on academic major and personal preference. The group was initially comprised of 16 students willing to devote three to five hours of work per week, with four students dropping out during the first half of the project due to personal situations unrelated to the design assignment itself. Preliminary meetings during the fall semester were held to clarify project goals, brainstorm ideas, and provide task assignments.

Students ranked their interest in joining one of three major research committees:

- Power and fuel system design, and orbital location decision

- Materials design, radiation hazards, cost assessment, and purpose(s) of station

- Physiological considerations, docking and rotation system design

The groups were then assigned to a committee based primarily on their highest ranked choices and secondarily on balancing committee representation. Everyone in each group was tasked with one or two subsystems or study topics. Each student was responsible for communicating with committee members, and with all other team members, to guarantee fluidity and correspondence of this highly interconnected project.

The student-led organization met weekly, and each committee presented their progress to the entire team. Students would then exchange evaluations, ask questions, and request revisions or further research for the following week. Each individual was also tasked with writing a brief report on their topic and what they learned. These written results were compiled into a document consisting of the whole group's findings. After 14 weeks conducting literature research, presenting, revising and integrating findings, the groups collaboratively compiled all the subsystems to create the completed design product.

At the milestone of submitting a pre-proposal to NASA, all participants were asked to complete online, non-identifying surveys inquiring about various aspects of their experience, motivations, and its perceived educational impact. Participants were asked, regardless of level of involvement, questions relating to what they gained overall and their ultimate impressions/conclusions. All 
survey questions had a multiple-choice format, some with the option of comparing impressions at different time points of the design project. Questions were tailored to expose the most important outcomes of such a large project based on student member suggestions, faculty mentor feedback, and prior research experience of group members.

\section{Results and Discussion}

Infrastructure and Design: The concept of choice resembles a bicycle wheel, consisting of a centralized globular support structure connected by long trusses to an outer habitat ring that encircles the entire station. The overall radius of this station from its center to the outer edge of the surrounding ring is 230 meters supported by Kevlar® cables.

Starting from the inside, the centerpiece to which everything connects to is a spherical shell measuring two meters in radius and made out of maraging steel. This allows it to suffer an extreme amount of force from all sides. There will also be a port in the sphere facing the axis of the wheel and two internal portals in the plane of the wheel. All three will function as airlocks with the port having an International Docking Attachment on a rotating ring so ships can dock there. The other two portals will be paths for personnel and equipment to pass to the outer section of the ship. These aluminum paths bridge the center piece to the outer ring and act as
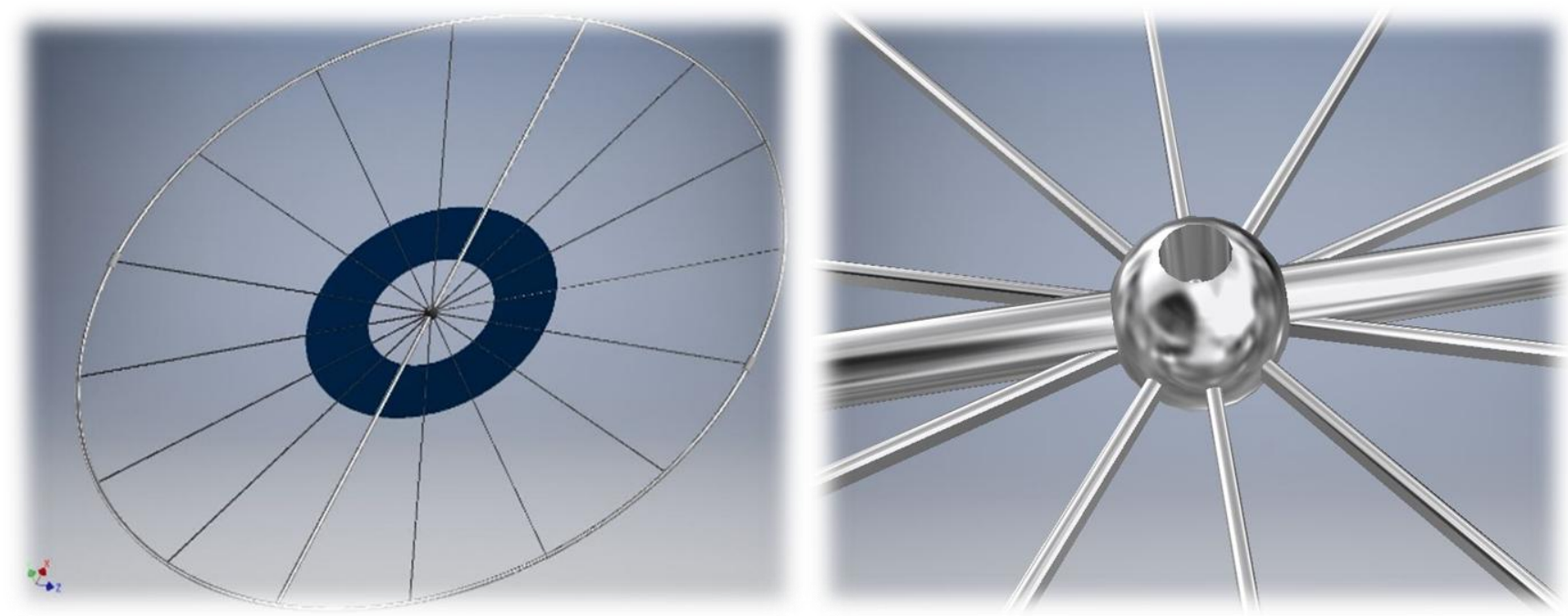

Figure 1: The station's outer ring with solar panels (left) and central docking sphere with connecting supports (right).

structural supports $^{1}$. These trusses will be symmetric and will be augmented by 16 Kevlar cables.

The largest part of the station is the outer ring. This is configured as a 142 sided polygon composed of different types of Bigelow Expandable Activity Modules (BEAM) ${ }^{2}$. The first type will make up 140 of the BEAMS, each cylindrical in shape, and have dimensions of 10 meters length and 1.83 meters radius. The second type will also be cylindrical but measure 20 meters in length and 3.05 meters in radius, creating two research and meeting facilities at either end of the ring. There will also be a third type, which will be used to build pressurized pathways from the outer ring to the center with dimensions of 10 meters length and one meter

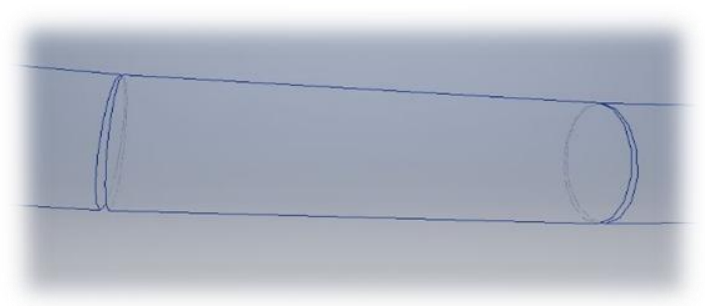

Figure 2: Cylindrical BEAM connections at $2.5^{\circ}$ angle. 
diameter. The interior of each beam will be unique, but all BEAM's will have an aluminum structure inside of them to help preserve their shape. The BEAM's will be connected end to end with each connection being at a slight $\sim 2.5$ degree tilt to give the outer ring a full 360 degrees circular appearance. A smaller, circular aluminum platform will be placed around the core to provide a self-tilting solar panel arrangement for powering the station. Upon assembly completion, every BEAM will also be coated in a $200 \mathrm{~mm}$ thick layer of hydrogenated boron nitride nanotube mesh to protect against radiation ${ }^{11}$. Four NEXT ion propulsion engines ${ }^{12}$ will be mounted on the outer ring at the intersection of each of the four aluminum support beams facing tangentially for rotation thrust or corrections.

Communication and Power: A substantial amount of power will supply the station $(757 \mathrm{~kW}$ scaled upwards from ISS requirements). Colloidal quantum dot solar panels are incorporated into the design for a total of 14,000 sq. meters of panels. This new processing technology significantly reduces panel costs while providing enough power to run five ECLSS systems, a full kitchen to cook for a 24 person crew, grow lights for agriculture, and all other electronics needed to operate the station. During the occultation period in geosynchronous orbit, an array of batteries (44 lithium ion AE-10 batteries) may provide power when briefly out of direct sunlight. The lifespan of these batteries are 15 years $^{3}$. Therefore, only 22 batteries are used during the first half of the 30 year operation of the station. Standard communication to Earth via radio will be used, backed up by the most updated versions of the Tracking and Data Relay Satellite Systems (TDRS).

Agriculture and Diet: Growing vegetables on an artificial gravity spacecraft is a challenge in which several experiments will need to be conducted to simulate conditions on board in space, including actual water consumption of plants and the amount of $\mathrm{CO}_{2}$ consumed by individual plants. It was only in 2015 that astronauts on the ISS were first able to grow and then eat lettuce grown in microgravity ${ }^{10}$. Such experiments will be conducted within the first five years of system operation to gather sufficient data for the remainder of the space station lifetime. The ECLSS system will be able to maintain the proper gas ratio and recycle evaporated water needed promote healthy plant growth. The key idea is that the plant habitat will need to be isolated to grow in a climate controlled environment. Several factors like temperature, humidity, oxygen/carbon dioxide ratio need to be closely monitored and adjusted. Each plant has different ideal conditions for maximum growth and yield, while some plants will have similar conditions and could be placed together in the same room to efficiently use the space needed to grow them. Most plants need humidity levels between 60 and 80 percent to keep living space comfortable, being kept separate from the living conditions of the astronauts ${ }^{4}$. The best concept for growing vegetables and legumes on this space station is hydroponics. This style of growing provides greater control of precious resources. It also allows for storage of water in reservoirs to prevent unnecessary evaporation. 


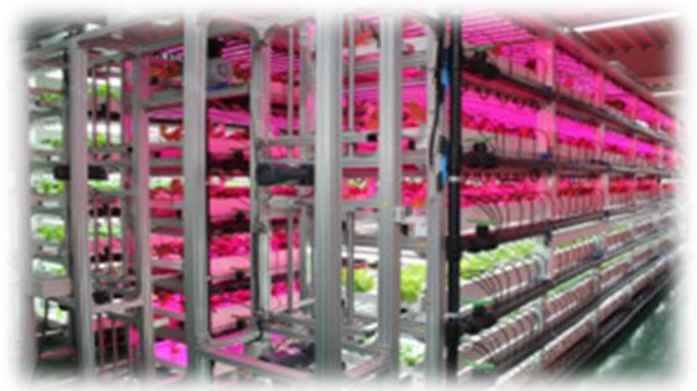

Figure 3: Vertical farming with hydroponics ${ }^{4}$.

When using hydroponics one has the ability to regulate water consumption, fertilizers, and $\mathrm{pH}$ adjustments on a consistent and precise basis. Each plant will have its own unique treatment with individualized water tanks to ensure proper nutrient balance. Including separate tanks reduces the risk of contamination or chemical imbalance. With the concept of vertical farming applied, stacking plant systems on top of each other will save floor space. Using hydroponics makes it much easier to water the plants, reducing the number of person-hours needed compared to using a conventional soil-based agriculture. Water is pumped from the top row and pseudo-gravity trickles the water through the remaining rows below and back to the reservoir. This ensures that the plants do not get overwatered, which could harm the plants by causing the roots to gum and not absorb nutrients. Vertical farming also allows the LED grow lights to be placed directly over the plants so they can absorb the highest amount of light intensity, increasing its ability to photosynthesize. Luckily, LED's do not produce high heat like conventional metal halide or sodium bulbs, so keeping them close to the plants will not increase their hydration intake by getting too hot. LED's are especially useful because they are compact in size and the light spectrum can be tailored to the exact wavelengths needed by the plant at any stage of growth. The energy required to run LED lights is $40 \%$ lower than incandescent bulbs while having a longer life span ${ }^{5}$.

Plant foods are chosen based on nutritional value (highest calorie density per vitamins and minerals) as well as antioxidant content to potentially help prevent cancer caused by space radiation. Yield and growth duration is second highest in priority to maximize production with the space available (126 cubic meters of growing space for a 24 person crew and 93 cubic meters for a 16 person crew based on food yield needed per number of yearly harvests).

\begin{tabular}{|c|c|c|c|c|c|c|c|c|}
\hline & Servings/day & Calories & Protein (g) & Fat (g) & Carbs (g) & Sugar (g) & Sodium (g) & Fiber (g) \\
\hline & & & & & & & & \\
\hline Grapes & 1 cup & 62 & 0.6 & 0.3 & 16 & 15 & 0.002 & 0.8 \\
\hline Tomato & 1 cup & 22 & 1.2 & 0.2 & 4.8 & 3.2 & 0.006 & 1.5 \\
\hline Potato & 1 whole & 163 & 4.3 & 0.2 & 37 & 1.7 & 0.013 & 4.7 \\
\hline Califlower & 1 cup & 27 & 2.1 & 0.3 & 5 & 2 & 0.032 & 2.1 \\
\hline Soy bean & $3 / 4$ cup & 622.5 & 51 & 27.75 & 42 & 10.5 & 0.003 & 12.75 \\
\hline Cucumber & 1 cup & 16 & 0.6 & 0.2 & 4 & 2 & 0.002 & 0.6 \\
\hline Carrot & 2 cup & 90 & 2 & 0.6 & 22 & 10 & 0.152 & 6.2 \\
\hline Avacado & 1 cup & 234 & 2.9 & 21 & 12 & 1 & 0.01 & 10 \\
\hline Pea & 2 cup & 236 & 16 & 1.2 & 42 & 16 & 0.14 & 14 \\
\hline Peanut & $1 / 2$ cup & 414 & 19 & 36 & 12 & 3 & 0.013 & 6 \\
\hline Broccoli & 1 cup & 31 & 2.6 & 0.3 & 6 & 1.5 & 0.03 & 2.4 \\
\hline & & & & & & & & \\
\hline Diet Total & & 1917.5 & 102.3 & 88.05 & 202.8 & 65.9 & 0.403 & 61.05 \\
\hline Body needs per/day & & 2000 & 50 & 70 & 310 & 90 & 2.3 & 30 \\
\hline
\end{tabular}

Figure 4: Plant foods chosen to occupy agriculture areas with listed nutritional fulfillments per one crew member ${ }^{6}$. 
Some macro nutrients, such as carbohydrates and protein, might not match with astronaut dietary preferences. However, with the variety of fruits and vegetables chosen, the diet can be manipulated over time to tailor an individual's needs.

Life Support Integration: The life support system aboard the spacecraft will play a vital role in the gas exchange between the plants and the crew. Since plants mainly consume carbon dioxide during the day and small amounts of oxygen at night, the exhaled $\mathrm{CO}_{2}$ by the crew can be used to supply the plants' needs. Meanwhile, the exhaled oxygen from the plants (about five milliliters per leaf) can be used to burn with the hydrogen byproduct from the Oxygen Generating System (OGS) to make water ${ }^{7}$. Using the excess hydrogen from the OGS is necessary, because of the high volume of plant waste which needs to be composted on-board. All remaining food scraps would go in a large heated vat for composting at $60^{\circ} \mathrm{C}$ to provide fresh growth medium in as early as three months. Because storing hydrogen in a spacecraft entails some risk, the gas could be burned as soon as it leaves one of the five ECLSS machines. This recycling system would match the average duration of plant growth periods so the crew does not produce more waste than can be recycled. Composting also recycles essential nutrients to feed new plant generations. Once the composting process is complete, water is filtered through the growth media to absorb the nutrients, then delivered to the hydroponic reservoirs to water the plants. After the growth media has been stripped of all usable nutrients, it can be gasified to produce hydrogen (for water) plus activated charcoal for filter elements.

\section{Mission Architecture:}

\section{Low Earth Orbit Assembly: Year 2020-2035}

The space station will launch in several segments for assembly in Low Earth Orbit (LEO). No reusability capabilities are assumed. A maximum of 13 Falcon Heavy launches, one Falcon 9 launch, and two SLS launches per year are possible and chosen for cost per kilogram efficiency and availability (see Appendix II). The station's core and basic power generation are launched first (phase one), followed by connecting struts and cables (phase two), and finally the inflatable modules that will make up the station's outer ring (phase three).

The central sphere and trusses will need to be carried by Falcon Heavy or SLS. Thirty-four of these will need to be launched for four trusses of seventeen segments each. Presumably, a slightly longer payload fairing could be made available for the truss segments without significantly affecting the launch vehicle's aerodynamics or lift capability. One FH or two F9s could be used to send up the Kevlar cabling. This neglects the mass of the spools or any other support equipment for the cables. If all sixteen cables can be enclosed in the Falcon's fairing, a single FH launch would be more economical. Four SLS 1B and nine Falcon Heavy launches over two years would be needed to launch all 142 BEAMs for the outer ring (12 modules per FH and 23 per SLS).

\section{$\underline{\text { Transport to Geosynchronous Orbit: Year 2035-2040 }}$}

Following construction, it will be slowly propelled from LEO to a non-equatorial geosynchronous orbit for the primary purpose of longitudinal research and deep space observation. Once in final position, four NASA Evolutionary Xenon Thruster (NEXT) ion thrusters, placed symmetrically at each aluminum truss connection at the outer ring, will bring 
the station to a two rpm rotation after 15.6 months of continual operation ${ }^{8}$. A series of cargo vessels and crew vehicles will also dock with the station, offloading equipment, supplies, and people. Close observation and analyzation of plant growth will be conducted.

Psychological Health of Crew: Both the psychological and physiological health of astronauts are equally vital. The absence of stimuli, or the isolation experienced during the mission, can cause deficiencies of dopamine in the human brain. Low dopamine levels cause symptoms that are similar to those of Post-Traumatic Stress Disorder (PTSD) and can also cause hyperactivity. This activation of the sympathetic nervous system leads to an inability to sleep, irritable and aggressive behavior, and deterioration in mental functioning. Huge amounts of stress are known to cause the hippocampus, responsible for memory, to shrink as well. All of these issues can interfere with the mission ${ }^{9}$. Astronauts will have to exercise using on-board equipment, maintain proper diet, listen to music, read books, do math problems, play space-conservative sports (i.e. ping pong), and practice crossword puzzles. These activities will engage their brain and maintain their ability to focus, make decisions, and respond more quickly to situations on-board. The interior of the spaceship will be covered with special designs similar to those used in hospitals to help astronauts orientate correctly. Paintings with certain colors that have a psychological influence on the human behavior could be incorporated as well (i.e. orange and blue color schemes). Caring for plant life also provides a positive therapeutic effect on astronauts and crew.

Radiation and Food Source: Every BEAM of the outer ring must be covered in a hydrogenated boron nitride $(\mathrm{BN})$ nanotube mesh to protect against radiation, shown to be most effective and space conserving compared to other existing technologies. Good diet and careful tracking of deep-space radiation bursts should help. Brominated materials incorporated into electrical systems where possible could also minimize fire risk.

Given that plant ecosystems are highly fragile and require constant care in an artificial environment, high-tech sensor systems must continually analyze plant health, inputs and outputs to the system, and quality of harvest. Frequent cargo exchange between Earth and the station should compare food quality

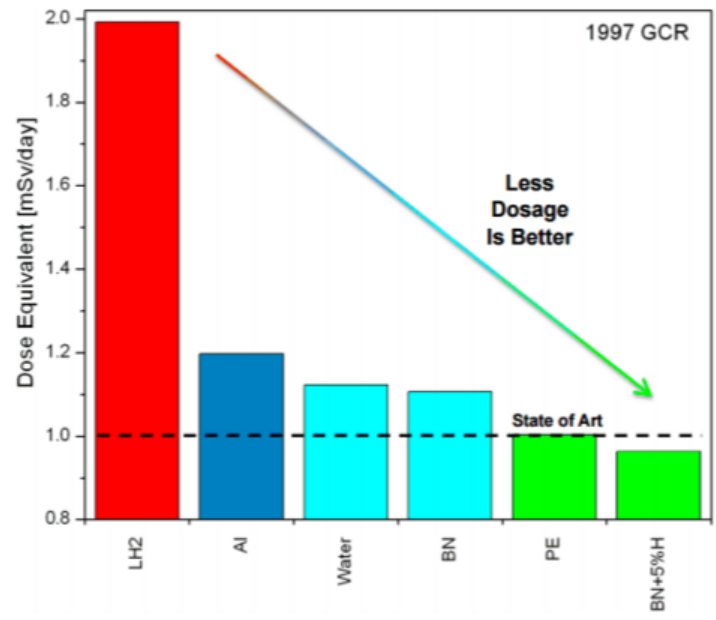

Figure 5: Sheila A, et al. 2012. Radiation Shielding Materials. NASA Langley Research outcomes within the first five years of operation. This should be one of the first systems to setup on-board during construction for close analysis and clearance of successful operation before establishing Earth-independence. Some emergency supplements must be stored on-board as well.

Annual Budget: Annual construction and launch costs for the first 15 years will average $\$ 610,441,796$ with minor deviations based on the mission phase. Operation startup between years 2035-2040 will theoretically incur relatively much lower costs.

\begin{tabular}{|l|l|l|l|}
\hline BILL OF MATERIALS & UNITS & UNIT PRICE & TOTAL COST \\
\hline Agri: Grow Lights & 400 & $\$ 600$ & $\$ 240,000$ \\
\hline Agri: Replacement Bulbs & 1600 & $\$ 200$ & $\$ 320,000$ \\
\hline Agri: Trough & 40 & $\$ 850$ & $\$ 34,000$ \\
\hline
\end{tabular}




\begin{tabular}{|l|l|l|l|}
\hline Agri: Water Reservoir & 8 & $\$ 300$ & $\$ 2,400$ \\
\hline Agri: Water Pump & 12 & $\$ 75$ & $\$ 900$ \\
\hline Agri: Trough Media & 360 & $\$ 20$ & $\$ 7,200$ \\
\hline Agri: Seeds & 50 & $\$ 84$ & $\$ 4,200$ \\
\hline Psych: Recreational Expenses & variable & variable & $\$ 8,000$ \\
\hline Psych: Hygienic Products & variable & variable & $\$ 7,500$ \\
\hline Psych: Exercise Equipment & variable & variable & $\$ 8,000$ \\
\hline $\begin{array}{l}\text { Psych: Viewing Port } \\
\text { Equipment }\end{array}$ & variable & variable & $\$ 50,000$ \\
\hline Life: Bedding & variable & variable & $\$ 5,000$ \\
\hline Life: ECLSS Systems & 5 & $\$ 2,500,000$ & $\$ 12,500,000$ \\
\hline $\begin{array}{l}\text { Life: Medical } \\
\text { Supplies/Equipment }\end{array}$ & variable & variable & $\$ 30,000$ \\
\hline Launch: (Rockets and fuel) & variable & variable & $\$ 6,250,000,000$ \\
\hline $\begin{array}{l}\text { Launch: Ion Drives and Xenon } \\
\text { Fuel }\end{array}$ & 4 & $\$ 1,250,000$ & $\$ 5,000,000$ \\
\hline Power: Solar Panels & 1400 & $\$ 20$ & $\$ 28,000$ \\
\hline Power: Solar Panel Batteries & 44 & $\$ 1,700$ & $\$ 74,800$ \\
\hline Structure: Kevlar Cables & 16 & $\$ 200,000$ & $\$ 3,200,000$ \\
\hline $\begin{array}{l}\text { Structure: Inflatable Ring } \\
\text { Tubes }\end{array}$ & 144 & $\$ 20,000,000$ & $\$ 2,880,000,000$ \\
\hline Structure: Central Sphere & 1 & $\$ 5,106,950$ & $\$ 5,106,950$ \\
\hline 20 YEAR TOTAL PROJECT EXPENSES & & $\$ 9,156,626,950$ \\
\hline
\end{tabular}

Technology Readiness Levels (TRL's): Presented below are the technology readiness levels of the major components of the $1 \mathrm{G}$ station.

\begin{tabular}{|l|l|}
\hline Component & TRL \\
\hline Station support structure elements & 8.0 \\
\hline International Docking Adaptor & 7.5 \\
\hline Bigelow Aerospace BEAMS & 7.0 \\
\hline BN Nanotube Mesh & 6.0 \\
\hline Agricultural System (in system isolation) & 7.0 \\
\hline
\end{tabular}

\section{Student Outcomes Analysis:}

The survey produced results from all 12 involved student members. Questions were designed to yield valuable results from multiple choice options. Because of the small size of the group, no statistical metrics were used, and only overall trends were analyzed.

Questions one, three, four, and 10 were designed to gather basic information about the students involved in the project. As can be seen below, question one asks summary information about the overall experience. The order of the survey questions was designed as to prevent other questions from interfering with the students' perception as the survey went on. As can be seen, the initial question yielded indicated very positive outcomes for the overall experience. 


\section{1: How would you rate your overall experience?}

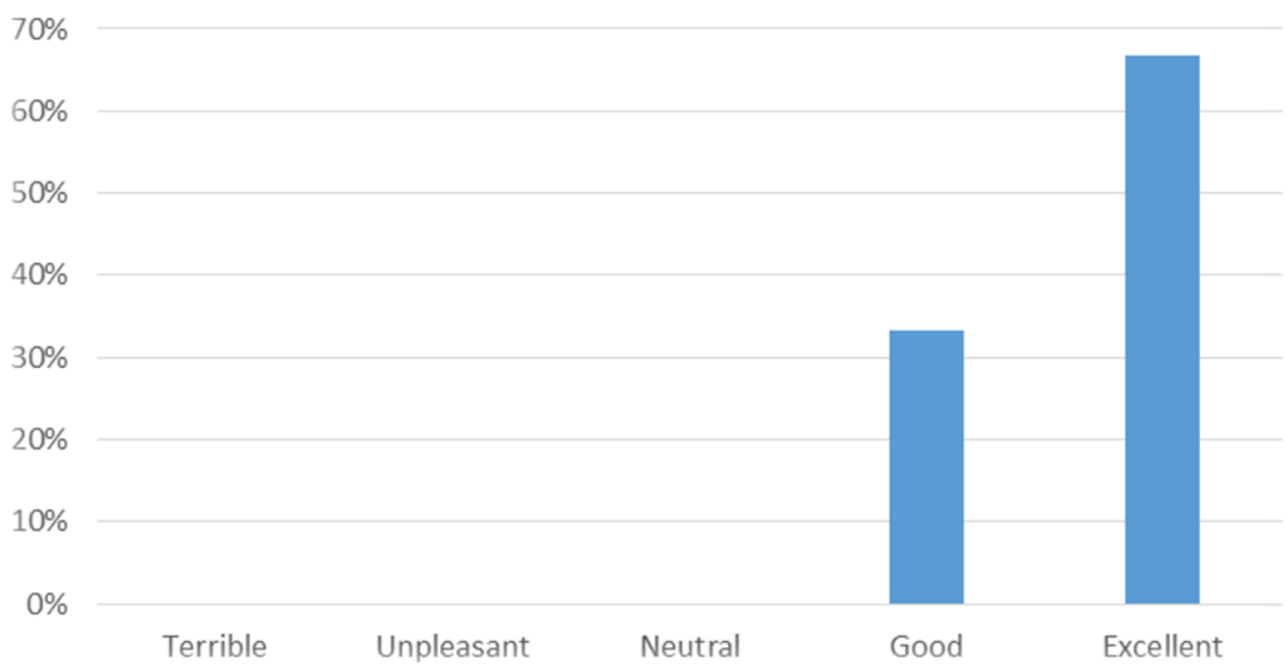

Figure 6: Student survey responses when asked "How would you rate your overall experience?" (N=12).

When asked how the students heard about the project, most students were either members prior to the start of the project or heard through some other means. Results of the "other" response are not shown but included "hearing from former students", "posted advertisements around campus", and "do not remember."

\section{3: How did you hear about the project?}

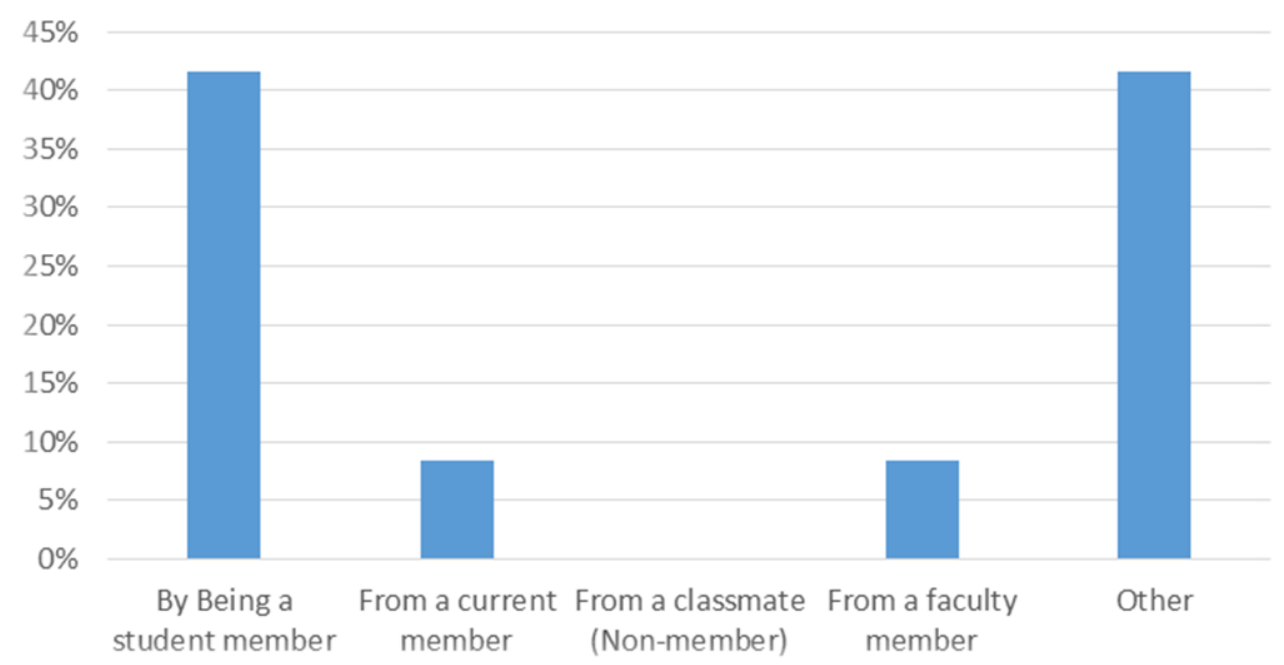

Figure 7: Student survey responses when asked "How did you hear about the project?" $(\mathrm{N}=12)$.

In considering the difficulty of such a large project, the attrition rate of student members was expected to be high. However, as the semester went on, only four students removed themselves from the project entirely due to personal reasons unrelated to the project itself. Question four was 
posed to find out what caused such a high retention of student members throughout the semester. As can be seen, most students remained involved in the project simply because of their individual level of interest in the topic. However, there were some students motivated to continue through the challenge by either the challenge itself, obligation to the group, or the desire for recognition through a potential publication. Considering the complexities of any student group, this distribution is surprisingly favorable to the research itself and shows that the topic was chosen well for this particular group.

\section{4: Please choose the top reason you chose to remain involved in the project throughout the semester.}

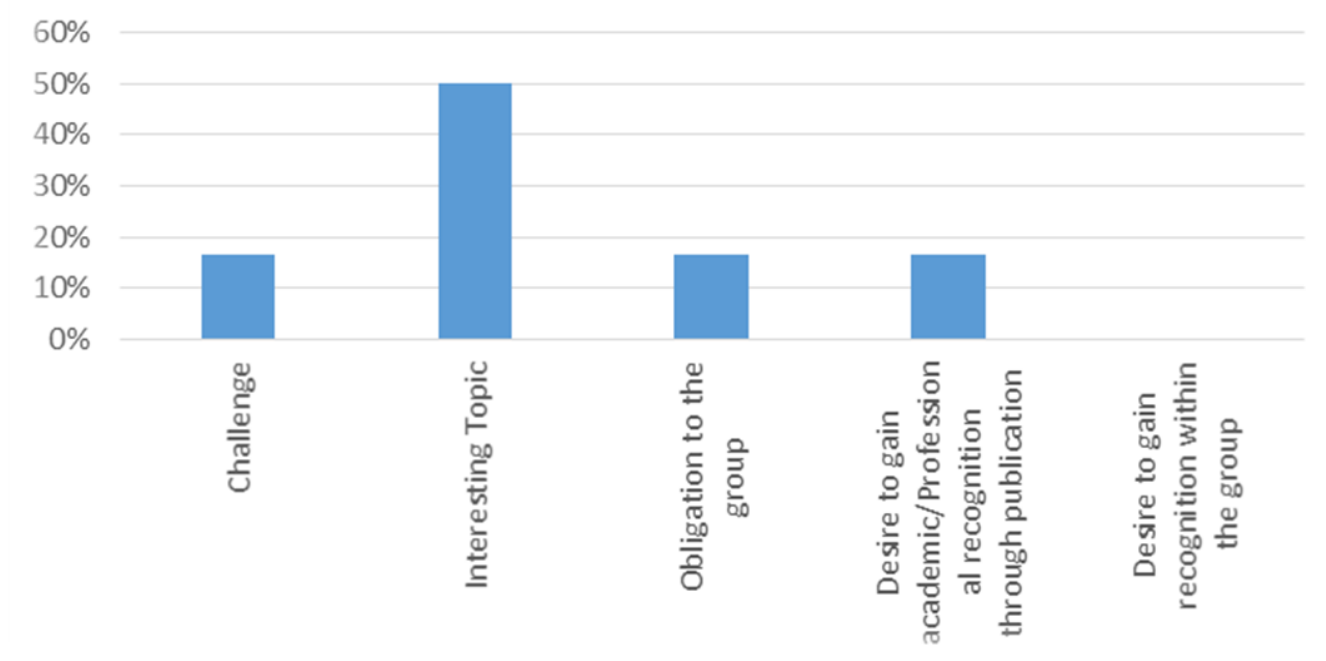

Figure 8: Student survey responses when asked to choose their reason for remaining involved in the project $(\mathrm{N}=12)$.

Question 10 was set up slightly differently to gauge students' attitudes at multiple points during the project. Students' appreciation for scientific research was questioned because it plays such a large role in any design concept project such as the one undertaken. It is important to note from the results that there was a very strong increase in scientific research as the project went on. This may be attributed to the assistance students received with research and that most students had never been a part of a complex research project prior to this project. 


\section{0: Please rate your attitude or appreciation for the following:}

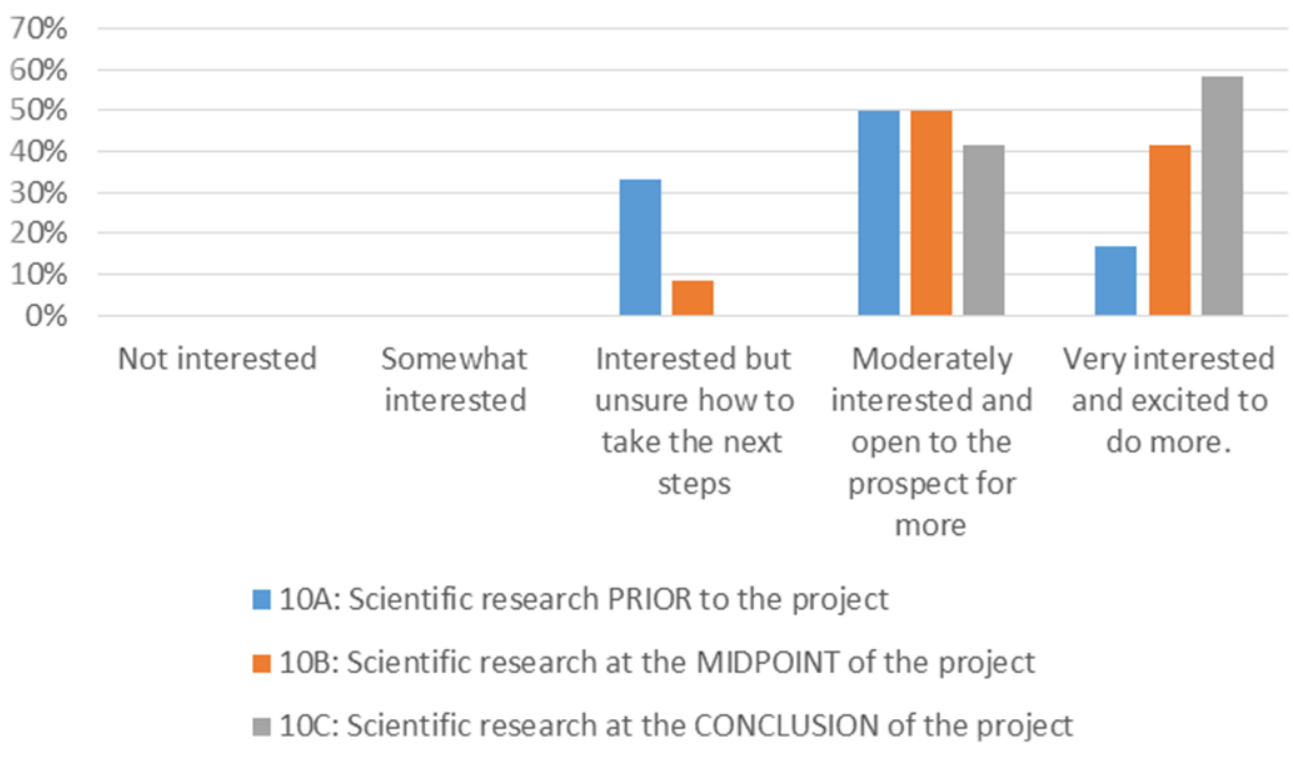

Figure 9: Student survey responses when asked to rate their attitude or appreciation for scientific research $(\mathrm{N}=12)$.

The second question in the survey was designed to gauge students' perceived value of the project as an effect on their knowledge of space technology and aerospace. As can be seen, the project has had an overwhelmingly strong impact on the students involved. Going forward, this question may be the single most important motivating factor for future projects. Projects chosen will be very challenging to help students expand their current understanding and knowledge in order to successfully complete the work being assigned. 


\section{2: Would you say this project has expanded your knowledge or awareness of space?}

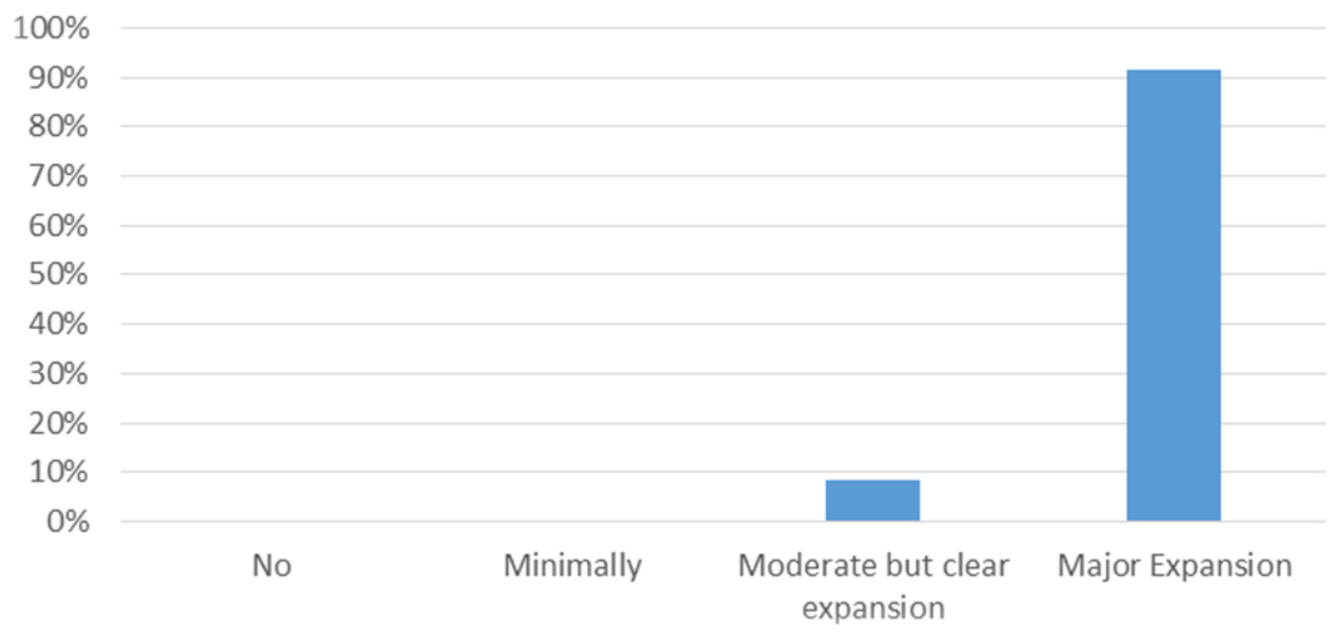

Figure 10: Student survey responses when asked "Would you say this project has expanded your knowledge or awareness of space?" ( $\mathrm{N}=12)$.

The next set of questions was designed to gather information about the students' feelings of ownership, interests/passions, skills, and how these were affected by the project. Question five asked about how students felt their interests and passions were taken into consideration for the project. It is excellent to see a strong correlation to students feeling like their individual interests were considered. With such a large group, it is quite surprising to not see more students feeling like their individual interests were not considered. The most likely explanation for this lies in the complexity of the project as so many different topics were covered. Also, many students seemed to feel as though the assigned topics were initially completely unknown to them and, after completing significant research into the topic, found the subject matter very interesting. In other words, through research, students began to find topics assigned interesting where they may not have prior to conducting the research. 


\section{5: Do you feel your interests / passions were taken into consideration with this project?}

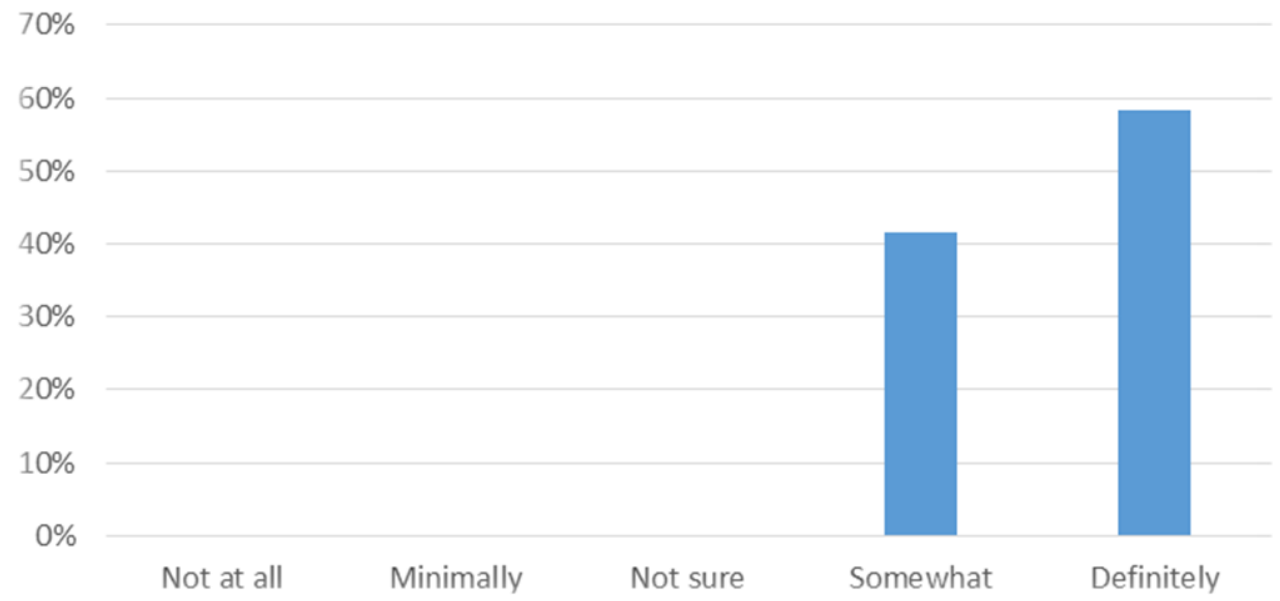

Figure 11: Student survey responses when asked "Do you feel your interests/passions were taken into consideration with this project?" $(\mathrm{N}=12)$.

Question six asked if students felt a sense of ownership of the project. This question is imperative to gauge how hard students are willing to work toward a common goal. The results are good, but it may be possible to improve on this section for future projects. Group leaders will take this data into account and attempt to eliminate all "Not sure" sections shown below to provide all students with at least some sense of ownership.

\section{6: Do you feel a sense of ownership for at least some of this project?}

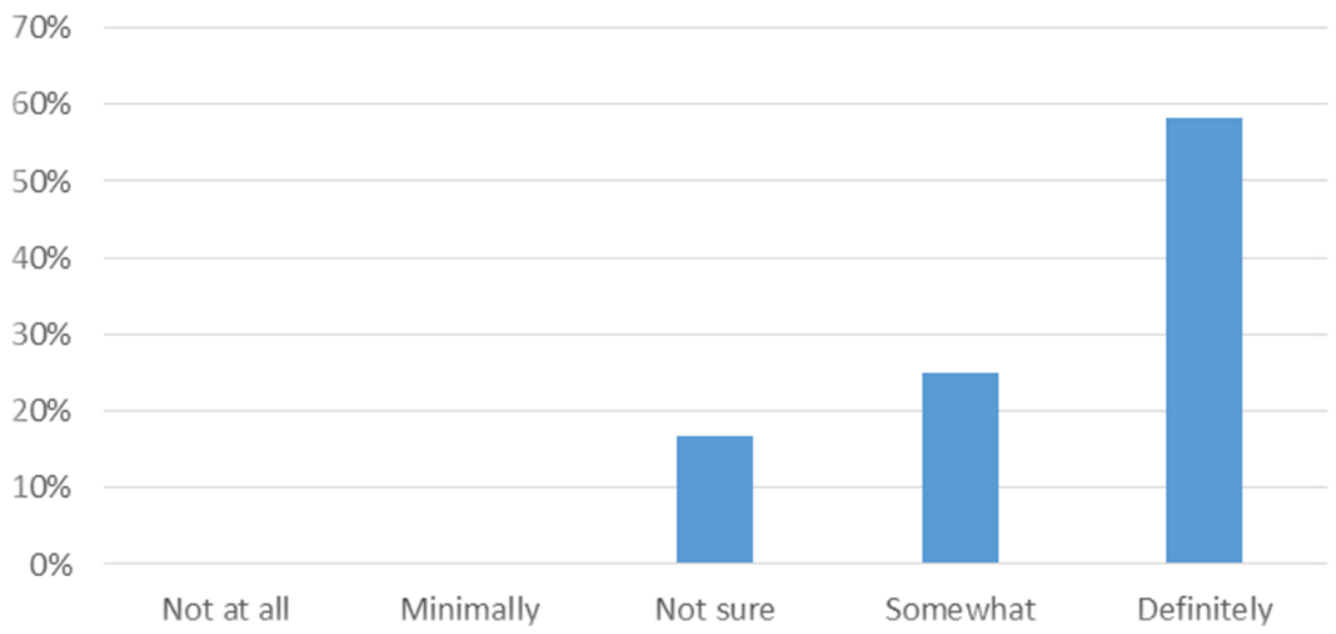

Figure 12: Student survey responses when asked "Do you feel a sense of ownership for at least some of this project?" $(\mathrm{N}=12)$. 
The final question in this section was to find out how students felt their individual skills were utilized by the group in the project. There was no expectation for this prior to asking the question as there are many disciplines grouped together including several engineering disciplines, physics, finance, and psychology. For the most part, the results were positive with one outlier as "minimally utilized". However, with a project of this scope, it is possible that all students involved cannot be utilized to the best of their ability as applicable to their specific skill set. Since this would encourage the students to expand their skills, the group does not see this as a negative response and will likely continue with the current plans in regards to this aspect.

\section{8: Do you feel as though you utilized your skills from your major in this project?}

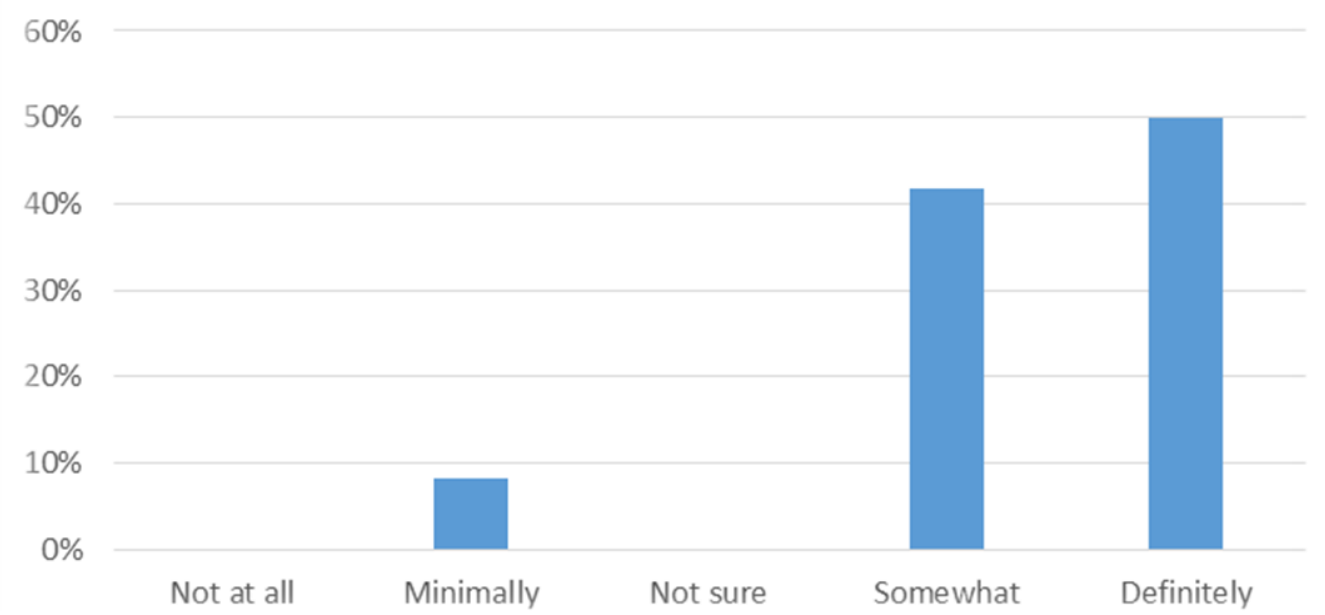

Figure 13: Student survey responses when asked "Do you feel as though you utilized your skills from your major in this project?" $(\mathrm{N}=12)$.

The final set of questions was designed to gauge how students perceive the success of the group. Question nine asked about how challenging the students found the project as the project went on. As can be seen, the perception moves from more challenging to more under control as the semester progresses. The organizational structure is the most likely cause of this change. The leadership of the group began to realize the scope of the project could be greatly enhanced with a very detailed project plan. Initially, the group was split into sections with little to no specificity in expectation of deliverable information. After only one month, this was seen as an inadequate method and each step was planned out, assigned, and given very specific expected deliverables with due dates that were challenging but possible to attain. This increased control for students is likely why the project began to seem challenging but under control. 


\section{9: This was a big, complex, difficult project. Check responses that apply to you.}

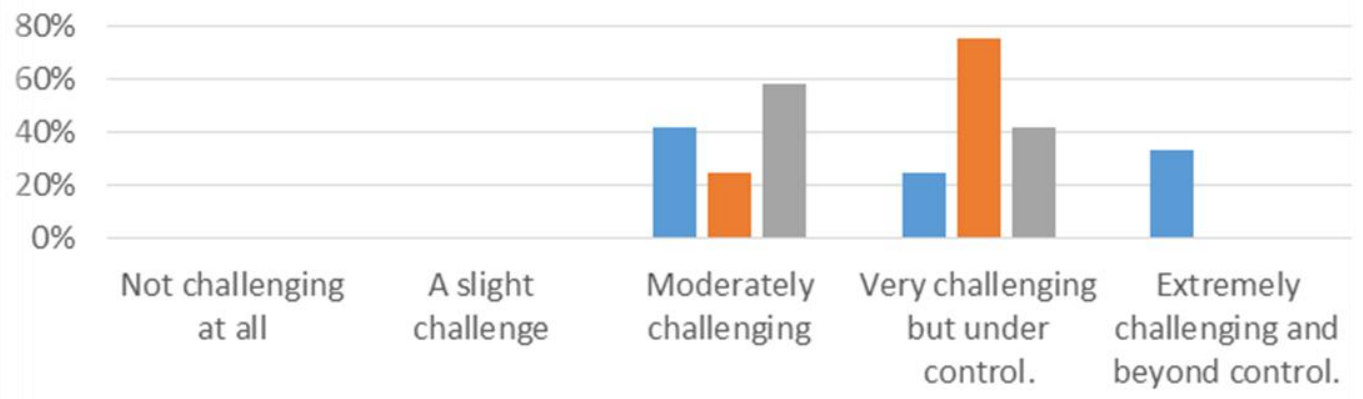

9A: How much of a challenge did you believe the project would be from the beginning?

9B: At the mid-point of the semester, how much of a challenge did you believe it was?

घC: Now, a full semester into the project, how much of challenge has it been to this point?

Figure 14: Student survey responses when about the challenge posed by this design project $(\mathrm{N}=12)$.

Question seven in this final set was to gather a retrospective view on the overall success of the project. With some of the project still remaining to be completed, this is a very important question to ask throughout the semester. The results are overwhelmingly positive and show the students' faith in the success of the project so far which bodes very well for the portion yet to come.

\section{7: Do you feel the project has been successful to this point}

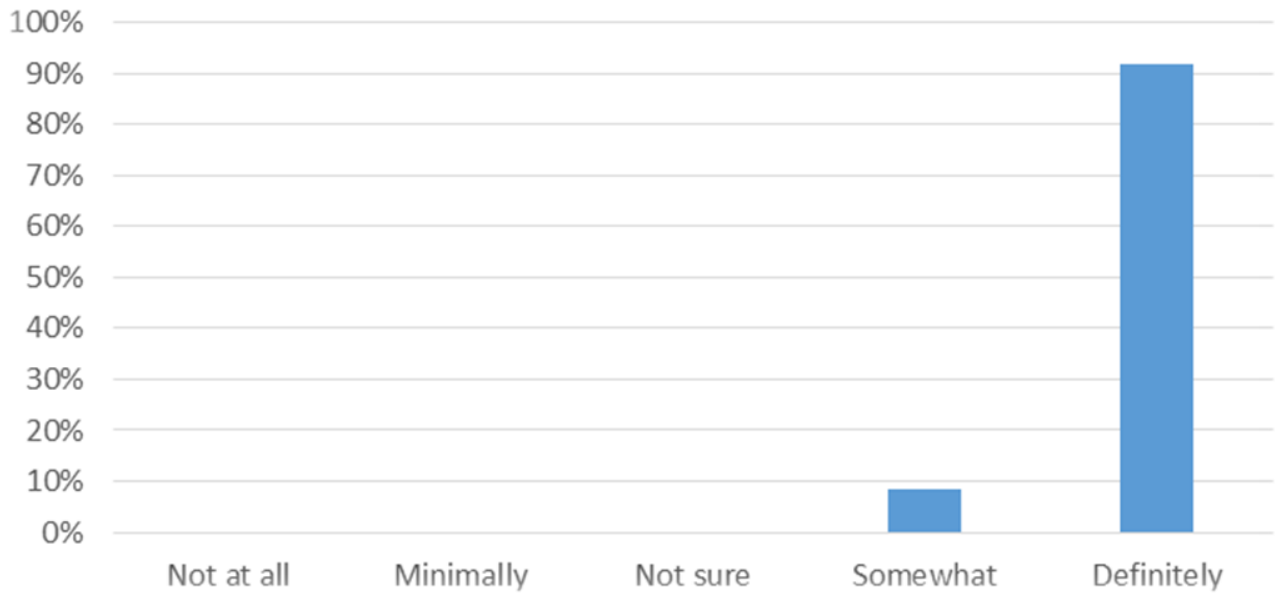

Figure 15: Student survey responses when asked "Do you feel the project has been successful to this point?" $(\mathrm{N}=12)$. 
Overall, the results of the survey show this project has had a very positive effect on students. From perceptions of success to feelings of being included and challenged, the group has become a cohesive unit with a focused goal of success. Regardless of background, skills, or interests, the group has found a way to include all members to meet the challenges of this very complex project. Based on these results, it is clear that nearly all students had an overall excellent experience, felt challenged and motivated within the context of an interesting topic, became progressively more excited about the project's implication throughout the study, and gained an enormous expansion of a personal sense of ownership and knowledge in aerospace design. Furthermore, successfully engaging a large, diverse team helped retain a range of interested and motivated students who ultimately felt that their individual passions were woven into the overall design approach. The results indicated a sense of student ownership and a feeling of project contribution, with identifying factors such as interest in aerospace topics studied, appropriate levels of challenge, and the prospect of communicating completed work to others contributing to sustained involvement. As expected, incorporating these features paired with an environment employing active learning strongly correlated with the evident success of the team. It can be seen that the leadership team and the engaged group at large has come together for the benefit of all students involved. Future similar educational initiatives shall continue to utilize this interconnected breadth of student considerations while further incorporating interspersed, indepth student self-assessments and generating more project themes that focus around a holistic, educational experience for everyone involved.

\section{Conclusion}

This work explored the knowledge development of a diverse team of undergraduate students involved in a university organization in pursuit of a RASC-AL engineering challenge by NASA to develop a 1-G deep space station. The breadth of considerations was well-suited for a large team with a broad range of skills. Teams collectively collaborated to present and successfully justify the most unique, practical, and cost-effective $1 \mathrm{G}$ space station design to implement a hands-on design experience. Individual passions were shown to provide a sense of ownership and a feeling of contribution, strongly correlating with overall feelings of success within the team. Leadership dynamics within the team influenced the perceived challenge of the design project at hand. Furthermore, knowledge of space and a positive outlook on research were both shown to increase as a result of the experience, thus attesting to the valuable impact of extracurricular engineering projects in the field of aerospace and beyond.

\section{References}

[1] Garcia, Mark. 2015. "Integrated Truss Structure," [Online]. Available: https://www.nasa.gov/mission_pages/station/structure/elements/its.html. [Accessed 20 November 2015].

[2] David, Leonard. 2013. "Inside NASA's Bigelow deal for inflatable space station room". MSNBC. [Accessed 20 November 2015].

[3] IDS Business Support. "International Space Station Electric Power System (EPS)," [Online].

[4] "Kind K3 L300 LED Grow Light - 220W." All Green Hydroponics [Online]. Available: http://allgreenhydroponics.com/products/kind-k3-1300-led-grow-light. [Accessed 22 Dec. 2015] 
[5] Albert, Steve. 2011. "Vegetable Crop Yields, Plants per Person, and Crop Spacing - Harvest to Table." Harvest to Table RSS. Available: http://www.harvesttotable.com/2011/06/. [Accessed 22 Dec 2015].

[6] Australian Food and Grocery Council. "Daily Intake Guide: Healthy eating, made easy. Front-of-pack labelling for food and drink in Australia. - Daily Intake Levels," [Online]. Available at: http://www.mydailyintake.net/daily-intake-levels/. [Accessed: 23 October 2015].

[7] "Oxygen Generator System." [Online]. NASA. Available at: http://www.nasa.gov/audience/foreducators/mathandscience/research/

[8] Globus, Al. 2015. "Space Settlement Population Rotation Tolerance." [Online]. Available at: http://www.nss.org/settlement/space/RotationPaper.pdf.

[9] Santy P. 2012. "The Journey Out and In: Psychiatry and Space Exploration." American Journal of Psychiatry.

[10] Aerospace America, pg. 60, Dec. 2015

[11] Thibeault, S.A., et al., "Radiation shielding materials containing hydrogen, boron and nitrogen," US patent application 20150248941 A1, 3 Sept 2015.

[12] Patterson, Michael. 2016. "NASA - Ion Propulsion.” NASA. [Online]. Available at: http://www.nasa.gov/centers/glenn/about/fs21 grc.html

[13] Bonwell, C.C., and J. A. Eison, "Active Learning: Creating Excitement in the Classroom," ASHEERIC Higher Education Report No. 1, George Washington University, Washington, DC, 1991.

[14] Maskell, D., "Student-Based Assessment in a Multi-Disciplinary Problem-Based Learning Environment", Journal of Engineering Education, v. 88 no. 4, pp. 237-241.

[15] Brodeur, D., et al. 2002. "Problem-Based Learning in Aerospace Engineering Education", Massachusetts Institute of Technology. Proceedings of the American Society for Engineering Education Annual Conference \& Exposition. 